\title{
LETTER
}

\section{One more idea on preventable ICU deaths ...}

\author{
Jan JM Ligtenberg*, Bas W Bens and Jack C ter Maaten \\ See related viewpoint by Dijkema et al., http://ccforum.com/content/16/2/309, and related research by de Souza et al., \\ http://ccforum.com/content/16/3/R72
}

In recent issues of Critical Care two papers regarding ICU mortality caught our eye: an interesting viewpoint article on preventable mortality by Dijkema and colleagues [1], and a research paper on the impact of ICU admission during morning rounds on mortality by de Souza and colleagues [2]. It appeared to us that an important factor to avoid preventable ICU deaths is not mentioned: the time period before the critically ill patient is finally admitted to the ICU.

As we know, early recognition of deteriorating patients in the nursing ward and in the emergency department followed by subsequent resuscitation treatment saves lives. The ICU patient admitted during morning rounds is usually already staying on the ward and has been deteriorating during the night: admission to the ICU might have been delayed during the night shift, resulting in a higher ICU mortality [2,3]. The same situation applies to patients admitted from the emergency department, who are treated according to the appropriate protocols but - for logistic or other reasons - may have to wait for their necessary admission to the ICU in an environment that may be less suitable after the first acute treatment and stabilization.
In our university-hospital-based emergency department with 34,000 patients/year, 579 patients were admitted to the ICU in 2011: the average time spent in the emergency department was 3 hours and 4 minutes. We think it might be useful to include measures to shorten the time period prior to ICU admission in the evaluation of preventable ICU deaths.

\section{Competing interests}

The authors declare that they have no competing interests.

Published: 6 July 2012

\section{References}

1. Dijkema LM, DieperinkW, van Meurs M, Zijlstra JG: Preventable mortality evaluation in the ICU. Crit Care 2012, 16:309.

2. de Souza IA, Karvellas CJ, Gibney RN, Bagshaw SM: Impact of intensive care unit admission during morning bedside rounds and mortality: a multicenter retrospective cohort study. Crit Care 2012, 16:R72.

3. Afessa B, Gajic O, Morales IJ, Keegan MT, Peters SG, Hubmayr RD: Association between ICU admission during morning rounds and mortality. Chest 2009, 136:1489-1495.

doi:10.1186/cc11371

Cite this article as: Ligtenberg JJM, et al:: One more idea on preventable ICU deaths ... Critical Care 2012, 16:438.
*Correspondence: j.j.m.ligtenberg@umcg.nl

Emergency Department, University Medical Center Groningen, Hanzeplein 1, 9700 RB, Groningen, The Netherlands 